Original Article

\title{
PROTECTIVE ROLE OF BERBERINE IN AMELIORATING DIABETIC COMPLICATIONS IN STREPTOZOTOCIN-HIGH FAT DIET MODEL IN EXPERIMENTAL ANIMALS
}

\author{
DEEPTI D. BANDAWANE ${ }^{*}$, SHRUTI B. MOOLIYA ${ }^{1}$, SHAILAJA B. JADHAV ${ }^{2}$
}

${ }^{1 *}$ Department of Pharmacology, PES's Modern College of Pharmacy, Yamunanagar, Nigdi, Pune, ${ }^{2}$ Department of Pharmaceutical Chemistry, PES's Modern College of Pharmacy, Yamunanagar, Nigdi, Pune

Email: deepti.bandawane@gmail.com

Received: 30 Apr 2020, Revised and Accepted: 08 Jun 2020

ABSTRACT

Objective: Diabetes mellitus is a serious, complex metabolic disorder and growing health threat disease in the world. Berberine, one of the main constituent in Rhizoma coptidis is widely used in the treatment of diabetes. Potential of berberine in the management of diabetic complications, namely diabetic nephropathy and cardiomyopathy, is however, not yet explored. The present study was, therefore, undertaken to explore the potential of berberine for the management of diabetic nephropathy and diabetic cardiomyopathy in high-fat diet (HFD) and low dose streptozotocin (STZ) induced diabetes in rats.

Methods: Rats were fed a high-fat diet for $4 \mathrm{w}$ followed by a single intraperitoneal dose of streptozotocin ( $35 \mathrm{mg} / \mathrm{kg})$. Animals were divided in five groups. Berberine was given orally in two different dose levels $(75 \mathrm{mg} / \mathrm{kg}$ and $150 \mathrm{mg} / \mathrm{kg}$ ) for $28 \mathrm{~d}$. Metformin $(100 \mathrm{mg} / \mathrm{kg})$ was used as a standard antidiabetic drug. At the end of the study, parameters evaluated includes glycemic profile, lipid profile, left ventricular indices, urinary protein, serum creatinine, blood urea nitrogen and cardiac antioxidants. Histopathology of kidney and pancreas was carried out.

Results: Berberine treated groups showed a significant decrease in fasting blood glucose, glycosylated $\mathrm{Hb}$, creatinine, blood urea nitrogen and urinary total proteins, whereas there was a significant improvement in serum insulin, liver glycogen, skeletal muscle glycogen and cardiac antioxidant enzymes.

Conclusion: Present study indicated that berberine shows a protective role in diabetes-associated renal and cardiovascular complications.

Keywords: Diabetic nephropathy, Diabetic cardiomyopathy, High fat diet, Streptozotocin, Berberine

(C) 2020 The Authors. Published by Innovare Academic Sciences Pvt Ltd. This is an open access article under the CC BY license (http://creativecommons.org/licenses/by/4.0/) DOI: http://dx.doi.org/10.22159/ijpps.2020v12i8.38096. Journal homepage: https://innovareacademics.in/journals/index.php/ijpps.

\section{INTRODUCTION}

Diabetes mellitus is one of the metabolic disorders characterized by abnormally high levels of blood glucose. It has been recognized as a growing worldwide epidemic by the World Health Organisation (WHO). Diabetes has become the disease of concern, particularly for Indians as India is now considered as the capital of diabetes patients, with 62.4 million Indians having type II diabetes mellitus [1]

In type II diabetes mellitus, progressive decline in insulin action referred as insulin resistance and pancreatic $\beta$-cell dysfunction leads to increased levels of blood glucose [2]. A major risk factor for insulin resistance is obesity, which is generally caused by a westernstyle high fatty diet and physical inactivity [3]. The development of insulin resistance in obesity exhibits accelerated lipolytic activity with increased release of free fatty acids (FFA) into the portal circulation. The FFA may be cytotoxic by inducing lipid peroxidation and hepatocyte apoptosis resulting in fatty liver disease. Further, studies have shown that both obesity and type II diabetes impair insulin-induced suppression of glycogenolysis and gluconeogenesis. The current treatment for type II diabetes includes insulin and oral hypoglycemic drugs such as biguanides, sulfonylurea derivatives, thiazolidinediones and $\alpha$-glucosidase inhibitors. These medications have side effects, e. g. thiazolidinediones induce obesity, osteoporosis and sodium retention; sulfonylurea derivatives can lead to incidences of severe hypoglycemia, whereas biguanides like metformin put patients at risk of developing lactic acidosis [4] Further, the oral monotherapy with lifestyle changes is not sufficient for most of the diabetic patients and requires various oral combinations or addition of insulin [5]. Thus, there is an increasing need to search for effective antidiabetic agents exhibiting fewer side effects. As an alternative, large number of population is trying to rely on plant-based remedies for management of this metabolic disorder.

Berberine is a natural alkaloid which is present in Hydrastis canadensis (goldenseal), Berberis vulgaris (barberry), Berberis aquifolium (Oregon grape), Coptis chinensis (Coptis or golden thread) and Berberis aristata (tree turmeric). Berberine is reported to be useful in the Indian traditional system since a long time for various ailments, including diabetes, hyperlipidemia, oxidative stress, cancer and inflammation [6-9]. Berberine is reported to exhibit antidiabetic activity through promoting regeneration and functional recovery of $\beta$-cells as well as by improvement of insulin sensitivity $[10,11]$. Considering the role of berberine as an insulin sensitizer, we have undertaken the present study with an objective to evaluate the effect of berberine on diabetic nephropathy and cardiomyopathy in HFDlow dose STZ induced type II diabetes in rats.

\section{MATERIALS AND METHODS}

\section{Drugs and chemicals}

Berberine was purchased from TCI Chemicals (India) Pvt Ltd. Streprozotocin (STZ) was purchased from Sigma chemicals, Germany. Kits for estimation of total cholesterol (TC), triglyceride (TG), highdensity lipoprotein (HDL), creatinine, blood urea nitrogen (BUN), total proteins, SGOT, SGPT and ALP were purchased from Erba diagnostics. All other chemicals used in study were of high-quality analytical grade.

\section{Experimental animals}

Healthy male Sprague Dawley rats (150-180 g) were procured from National Institute of Bioscience, Chaturshrungi, Pune. Animals were housed in a group of 6 per cage in standard polypropylene cages lined with raw husk. The animal house was maintained on $12 \mathrm{~h}$ light/dark cycle at approximately $22 \pm 2{ }^{\circ} \mathrm{C}$, relative humidity 60 $70 \%$. After randomization into various groups and before initiation of the experiment, the rats were acclimatized for a period of $7 \mathrm{~d}$. Before and during the experiment rats were fed with standard laboratory diet (Nutrivet Lifescience, Pune, Maharashtra) and water ad libitum. All experimental procedures were carried out in accordance to Institutional Animal Ethics Committee (IAEC) as per the CPCSEA guidelines (Approval No-MCP/IAEC/009/2017). 


\section{Induction of diabetes mellitus}

Rats were given a high-fat diet $(58 \%$ fat, $25 \%$ protein and $17 \%$ carbohydrate, as a percentage of total kcal), the composition of which was slightly modified as per documented by Srinivasan $\mathrm{K}$ [12]. After $4 \mathrm{w}$, rats were injected STZ $(35 \mathrm{mg} / \mathrm{kg}$, i. p.) prepared freshly in cold citrate buffer (pH 4.5). Seven d after STZ injection, rats showing fasting blood glucose level more than $200 \mathrm{mg} / \mathrm{dl}$ were considered diabetic.

\section{Experimental design}

Animals were divided into five groups, each consisting of six rats as follows.

Group I: Normal control rats, administered saline $(0.9 \% \mathrm{w} / \mathrm{v})$ for $28 \mathrm{~d}$

Group II: Diabetic control rats received HFD for $4 \mathrm{w}$ followed by a single intraperitoneal dose of STZ (35 mg/kg)

Group III: Diabetic rats received metformin $(100 \mathrm{mg} / \mathrm{kg})$ for $28 \mathrm{~d}$

Group IV: Diabetic rats received berberine $(75 \mathrm{mg} / \mathrm{kg}$ ) for $28 \mathrm{~d}$

Group V: Diabetic rats received berberine $(150 \mathrm{mg} / \mathrm{kg})$ for $28 \mathrm{~d}$

At the end of the study period, rats were fasted overnight, sacrificed and serum separated from collected blood samples for various biochemical estimations.

\section{Measurement of physical parameters}

During the treatment period, body weight, food intake and water intake of rats were recorded and the change in these parameters was calculated. Basal metabolic index (BMI) calculated as per formula [13].

$$
\text { Basal metabolic index }(\mathrm{BMI})=\frac{\text { Body weight }(\mathrm{g})}{\text { Height }(\mathrm{cm} 2)}
$$

\section{Evaluation of antihyperglycemic parameters}

\section{Blood glucose estimation}

Fasting blood glucose level was determined in all experimental rats initially to determine the diabetic status and thereafter every week during the $28 \mathrm{~d}$ study period.

\section{Oral glucose tolerance test (OGTT)}

OGTT was performed in overnight fasted $(18 \mathrm{~h})$ rats at the end of $28^{\text {th }} \mathrm{d}$ of the study period. All experimental groups were fed with glucose $(4 \mathrm{~g} / \mathrm{kg}) 30 \mathrm{~min}$ after the administration of drugs. Blood glucose was determined at $0,30,60,90$ and $120 \mathrm{~min}$ of glucose administration [14].

\section{Estimation of biochemical parameters}

At the end of $28 \mathrm{~d}$, blood was subjected for determination of glycosylated hemoglobin and serum for the determination of insulin. Liver and skeletal muscles of individual rats were homogenised in $5 \% \mathrm{w} / \mathrm{v}$ trichloroacetic acid and its glycogen content was determined by the method of Carrol [15].

\section{Evaluation of diabetic cardiomyopathy}

\section{Lipid profile}

At the end of $28 \mathrm{~d}$, blood was collected from inferior vena cava serum separated and subjected for determination of parameters like total cholesterol (T-CH), high-density lipoproteins (HDL-CH) and triglycerides (TG) using commercially available kits. Very lowdensity lipoproteins (VLDL-CH) and low-density lipoproteins (LDL$\mathrm{CH})$ were calculated using the Friedewald's formula [16, 17]. Atherogenic index (AI) and coronary risk index (CRI) were calculated as an indicator for atherosclerotic lesion and coronary atherosclerosis development, respectively $[18,19]$.

\section{Cardiac and left ventricular hypertrophic indices}

At the end of the experiment, the heart was blotted with filter paper to remove an excess of water. Extraneous tissues from the heart were removed and the weight of the heart was noted. Index of hypertrophy was calculated as the ratio of heart weight to body weight (HW/BW) using the following formula [20].

$$
\text { Cardiac Hypertrophy Index }=\frac{\text { Heart weight }(\mathrm{g})}{\text { Bodyweight }(\mathrm{g})}
$$

Left ventricle of the heart was isolated and weighed. Left ventricular hypertrophy index was calculated using the following formula:

$$
\text { Left ventricular hypertrophy index }=\frac{\text { Left ventricular weight }(\mathrm{mg})}{\text { Bodyweight }(\mathrm{g})}
$$

Evaluation of cardiac anti-oxidant activity

Estimation of superoxide dismutase (SOD)

The SOD activity was measured according to the method of Marklund [21].

Estimation of catalase (CAT)

Catalase was measured according to the method described by Sahreen et al. [22].

\section{Estimation of MDA lipid peroxidation}

MDA lipid peroxidation was estimated according to the method described by Kumar et al. [23].

\section{Evaluation of diabetic nephropathy}

The $24 \mathrm{~h}$ urine sample collected from each rat was centrifuged. Urinary total protein, as well as plasma uric acid, plasma urea, serum creatinine and blood urea nitrogen, were determined using commercial kits. Kidney hypertrophy index was estimated as per the following formula [12].

$$
\text { Kidney hypertrophy index }=\frac{\text { Kidney weight }(\mathrm{g}) \times 100}{\text { Bodyweight }(\mathrm{g})}
$$

\section{Histopathological studies}

Pancreas and kidney samples of rats were isolated and fixed in 10\% neutral buffer formalin, rinsed by xylene and embedded in paraffin. Tissue sections (5 $\mu \mathrm{m}$ thickness) were cut and stained with hematoxylin-eosin (HE) dye for histopathological examination using light microscopy [24].

\section{Statistical analysis}

All results were expressed as the mean \pm SEM. p-value of $<0.05$ was considered statistically significant. The data was analysed for statistical significance by one-way analysis of variance (ANOVA) followed by Dunnet's multiple test for comparison. GraphPad Instat version 3 was the statistical software used for analysis.

\section{RESULTS}

\section{Effect on parameters of the antihyperglycemic study}

Effect of berberine on blood glucose level in diabetic rats is shown in fig. 1 . A sustained and significant $(\mathrm{p}<0.001)$ decrease in blood glucose level was observed in dose dependent manner in berberine treated groups during $28 \mathrm{~d}$ period as compared to diabetic control.

Table 1 depicts the effect of a single oral administration of berberine on glucose tolerance, which exhibited a maximum fall in postprandial glucose level at $30 \mathrm{~min}$.

As shown in table 2, oral administration of berberine significantly restored the levels of glycosylated haemoglobin $(\mathrm{p}<0.001)$ and serum insulin $(\mathrm{p}<0.01)$ in diabetic rats. Oral administration of berberine for $28 \mathrm{~d}$ significantly $(\mathrm{p}<0.001)$ restored the decreased glycogen content in liver and skeletal muscles in diabetic rats. 


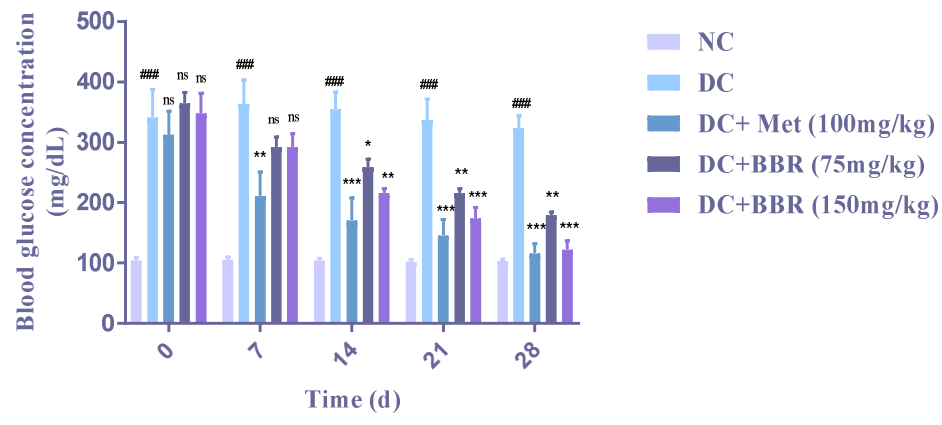

Fig. 1: Effect of oral administration of berberine on fasting blood glucose level, Values are expressed as mean \pm SEM \#\#p value $<0.01$, \#\#\#p value $<0.001$ as compared to $\mathrm{NC},{ }^{*} \mathrm{p}$ value $<0.05,{ }^{* *} \mathrm{p}$ value $<0.01,{ }^{* * *} \mathrm{p}$ value $<0.001$ as compared to DC

Table 1: Effect of berberine (BBR) on oral glucose tolerance test

\begin{tabular}{lllll}
\hline Experimental groups & \multicolumn{2}{l}{ Blood glucose $\mathbf{m g} / \mathbf{d l})$} & & \\
\cline { 2 - 5 } & $\mathbf{0}$ min & $\mathbf{3 0}$ min & $\mathbf{6 0}$ min & $\mathbf{9 0}$ min \\
\hline Normal Control (NC) & $85.5 \pm 3.50$ & $109.3 \pm 3.34$ & $102 \pm 5.15$ & $99.83 \pm 4.5$ \\
Diabetic Control (DC) & $469.8 \pm 11.6^{\# \#}$ & $544.8 \pm 6.5^{\# \# \#}$ & $560 \pm 4.3^{\# \# \#}$ & $530.7 \pm 5.51^{\# \# \#}$ \\
DC+MET (100 mg/kg) & $141.5 \pm 3.9$ & $157.5 \pm 5.1^{* *}$ & $157.7 \pm 4.6^{* *}$ & $135.7 \pm 4.8^{* * *}$ \\
DC+BBR (75 mg/kg) & $163.5 \pm 2.54$ & $204.5 \pm 3.8^{\text {ns }}$ & $192.3 \pm 4.7^{*}$ & $172.8 \pm 6.24^{*}$ \\
DC+BBR (150 mg/kg) & $159.3 \pm 7.6$ & $181.2 \pm 4.06^{*}$ & $168.5 \pm 4.4^{* *}$ & $151.0 \pm 4.6^{* *}$ \\
\hline
\end{tabular}

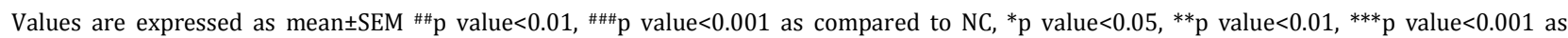
compared to DC

Table 2: Effect of berberine (BBR) on biochemical parameters

\begin{tabular}{|c|c|c|c|c|c|}
\hline Biochemical parameters & $\begin{array}{l}\text { Normal control } \\
\text { (NC) }\end{array}$ & $\begin{array}{l}\text { Diabetic control } \\
\text { (DC) }\end{array}$ & $\begin{array}{l}\text { DC+MET (100 } \\
\mathrm{mg} / \mathrm{kg})\end{array}$ & $\begin{array}{l}\text { DC+BBR (75 } \\
\mathrm{mg} / \mathrm{kg})\end{array}$ & $\begin{array}{l}\text { DC+BBR (150 } \\
\mathrm{mg} / \mathrm{kg})\end{array}$ \\
\hline Glycosylated haemoglobin (\%) & $6.38 \pm 0.25$ & $9.3 \pm 0.27 \# \# \#$ & $6.8 \pm 0.22^{* * *}$ & $7.41 \pm 0.2^{* *}$ & $6.93 \pm 0.2^{* * *}$ \\
\hline Serum insulin $(\mu \mathrm{IU} / \mathrm{ml})$ & $10.09 \pm 0.52$ & $3.51 \pm 0.3^{\# \# \# ~}$ & $6.47 \pm 0.21^{* * *}$ & $5.25 \pm 0.23^{*}$ & $6.02 \pm 0.19^{* *}$ \\
\hline $\begin{array}{l}\text { Glycogen content in skeletal } \\
\text { muscles }(\mathrm{mg} / 100)\end{array}$ & $48 \pm 1.8$ & $9.8 \pm 1^{\# \#}$ & $41.7 \pm 1.2^{* * *}$ & $35.7 \pm 1.3^{* * *}$ & $39.3 \pm 0.9^{* * *}$ \\
\hline $\begin{array}{l}\text { Glycogen content in liver } \\
(\mathrm{mg} / 100)\end{array}$ & $24.83 \pm 1.9$ & $9.7 \pm 1.2^{\# \# \# ~}$ & $23.17 \pm 2^{* * *}$ & $16.33 \pm 1.9^{*}$ & $21.7 \pm 1.9^{* * *}$ \\
\hline
\end{tabular}

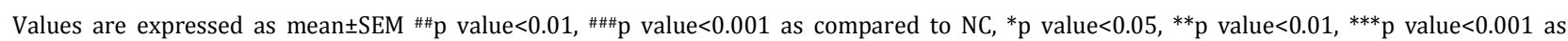
compared to DC

\section{Effect on parameters of diabetic cardiomyopathy}

As shown in fig. 2, diabetic rats treated with berberine showed a significant reduction in the elevated levels of total cholesterol $(\mathrm{p}<0.01)$, triglyceride $(\mathrm{p}<0.001), \mathrm{LDL}-\mathrm{CH}(\mathrm{p}<0.01)$ and VLDL-CH $(p<0.05)$ in diabetic rats. On the contrary, there was significant $(\mathrm{p}<0.01)$ improvement in HDL-CH level in BBR treated groups as compared to diabetic control.

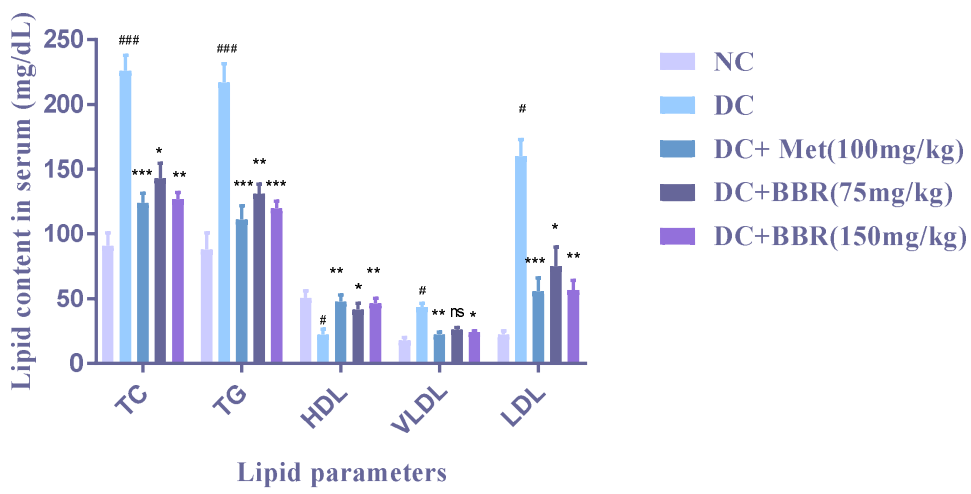

Fig. 2: Effect of berberine (BBR) on lipid profile, values are expressed as mean \pm SEM \#\#p value $<0.01$, \#\#\#p value<0.001 as compared to NC, ${ }^{*}$ p value $<0.05,{ }^{* *}$ p value $<0.01,{ }^{* * *}$ p value $<0.001$ as compared to $\mathrm{DC}$ 
As shown in table 3, there was a significant increase in myocardia MDA, whereas a decrease in SOD and CAT levels in diabetic control rats. Berberine treatment exhibited significant $(\mathrm{p}<0.01)$ reduction in myocardial MDA with a significant increase in SOD $(\mathrm{p}<0.001)$ and CAT $(\mathrm{p}<0.01)$ levels of myocardium in treatment groups compared to diabetic control rats. There was a significant reduction in cardiac hypertrophy index $(\mathrm{p}<0.001)$, left ventricular hypertrophy index $(\mathrm{p}<0.01)$ and heart weight $(\mathrm{p}<0.001)$ after berberine treatment. As shown in table 3 , berberine at dose of $150 \mathrm{mg} / \mathrm{kg}$ showed significant $(\mathrm{p}<0.001)$ reduction in atherogenic and coronary risk indices.

Table 3: Effect of berberine (BBR) on cardiac parameters

\begin{tabular}{|c|c|c|c|c|c|}
\hline Parameters & $\begin{array}{l}\text { Normal control } \\
\text { (NC) }\end{array}$ & $\begin{array}{l}\text { Diabetic } \\
\text { control (DC) }\end{array}$ & $\begin{array}{l}\text { DC+MET (100 } \\
\mathrm{mg} / \mathrm{kg})\end{array}$ & $\begin{array}{l}\text { DC+BBR (75 } \\
\mathrm{mg} / \mathrm{kg})\end{array}$ & $\begin{array}{l}\text { DC+BBR (150 } \\
\mathrm{mg} / \mathrm{kg})\end{array}$ \\
\hline SOD (U/mg of protein) & $12.66 \pm 0.57$ & $3.86 \pm 0.5^{\# \# \#}$ & $11.64 \pm 0.8^{* * *}$ & $8.82 \pm 0.6^{* *}$ & $10.71 \pm 0.5^{* * *}$ \\
\hline $\begin{array}{l}\text { CAT }\left(\mu \mathrm{moles} \text { of } \mathrm{H}_{2} \mathrm{O}_{2}\right. \\
\text { utilized } / \mathrm{min} / \mathrm{mg} / \text { protein })\end{array}$ & $77.90 \pm 4.64$ & $34.17 \pm 2.2^{\# \# \# ~}$ & $60.38 \pm 3.6^{* * *}$ & $51.84 \pm 3.04^{*}$ & $51.52 \pm 2.5^{* *}$ \\
\hline $\operatorname{MDA}(\mu \mathrm{mol} /$ gram $)$ & $200.42 \pm 4.6$ & $396.2 \pm 20.8^{\# \# \#}$ & $206.6 \pm 5.9^{* * *}$ & $227.5 \pm 7.61^{*}$ & $216.44 \pm 3.5^{* *}$ \\
\hline Cardiac hypertrophy (mg/gram) & $7.918 \pm 0.14$ & $6.35 \pm 0.17^{\# \#}$ & $6.2 \pm 0.19^{* * *}$ & $5.83 \pm 0.12^{* *}$ & $6.05 \pm 0.2^{* * *}$ \\
\hline $\begin{array}{l}\text { Left Ventricular hypertrophy } \\
\text { (mg/gram) }\end{array}$ & $0.65 \pm 0.01$ & $0.7 \pm 0.013^{\# \#}$ & $0.64 \pm 0.01^{* * *}$ & $0.72 \pm 0.008$ & $0.69 \pm 0.009^{* *}$ \\
\hline Atherogenic risk index & $0.78 \pm 0.06$ & $9.6 \pm 2.76^{\# \# \#}$ & $1.7 \pm 0.41^{* * *}$ & $2.48 \pm 0.7^{* *}$ & $1.8 \pm 0.34^{* * *}$ \\
\hline Cardiac risk index & $1.78 \pm 0.03$ & $10.6 \pm 2.8^{\# \# \#}$ & $2.7 \pm 0.41^{* * *}$ & $3.48 \pm 0.7^{* *}$ & $2.7 \pm 0.32^{* * *}$ \\
\hline Heart weight (mg) & $1.25 \pm 0.94$ & $1.7 \pm 0.03^{\# \# \#}$ & $1.2 \pm 0.01^{* * *}$ & $1.26 \pm 0.01^{* *}$ & $1.2 \pm 0.01^{* * *}$ \\
\hline
\end{tabular}

Values are expressed as mean \pm SEM \#\#p value $<0.01$, \#\#\# value $<0.001$ as compared to $\mathrm{NC},{ }^{*} \mathrm{p}$ value $<0.05,{ }^{* *} \mathrm{p}$ value $<0.01,{ }^{* * *} \mathrm{p}$ value $<0.001$ as compared to DC

\section{Effect on parameters of diabetic nephropathy}

As shown in the table 4 , there was a significant increase $(\mathrm{p}<0.01)$ in serum urea, serum creatinine and blood urea nitrogen in diabetic control rats. Berberine treatment exhibited significant $(\mathrm{p}<0.01)$ reduction in these renal parameters as compared to diabetic control rats. The urine volume $(24 \mathrm{~h})$ of diabetic rats was found to be significantly increased as compared to the normal control group. After $28 \mathrm{~d}$ of treatment with berberine, urine volume significantly $(\mathrm{p}<0.01)$ reduced as compared to diabetic control.

\section{Effect on physical parameters}

Table 5 shows that the bodyweight of diabetic rats was significantly $(p<0.001)$ increased as compared to the normal rats throughout the experimental period. After treatment with berberine, the bodyweight significantly $(\mathrm{p}<0.05)$ reduced as compared to diabetic control groups. Moreover, diabetic rats showed a significant increase $(p<0.001)$ in food intake as compared with the normal group. Oral administration of berberine for $28 \mathrm{~d}$ significantly $(\mathrm{p}<0.01)$ reduced food intake as compared to diabetic control. At the end of the study period, a significant decrease $(\mathrm{p}<0.01)$ in the water intake was observed in berberine treated groups as compared to diabetic control.

Table 4: Effect of berberine (BBR) on renal parameters

\begin{tabular}{lllll}
\hline Renal parameters & $\begin{array}{l}\text { Normal control } \\
\text { (NC) }\end{array}$ & $\begin{array}{l}\text { Diabetic control } \\
\text { (DC) }\end{array}$ & $\begin{array}{l}\text { DC+MET (100 } \\
\text { mg/kg) }\end{array}$ & $\begin{array}{l}\text { DC+BBR (75 } \\
\text { mg/kg) }\end{array}$ \\
\hline Urinary protein (mg/dl) & $6.38 \pm 0.25$ & $9.26 \pm 0.27^{\# \# \#}$ & $6.75 \pm 0.22^{* * *}$ & $7.41 \pm 0.20^{* *}$ \\
Serum creatinine (mg/dl) & $0.348 \pm 0.02$ & $0.94 \pm 0.043^{\# \#}$ & $0.4 \pm 0.02^{* * *}$ & $6.93 \pm 0.21^{* * *}$ \\
BUN (mg/dl) & $66.37 \pm 2.6$ & $185.4 \pm 4.75^{\# \#}$ & $110.5 \pm 2.9^{* * *}$ & $0.53 \pm 0.265^{*}$ \\
Serum Uric acid (mg/dl) & $1.3 \pm 0.21$ & $2.28 \pm 0.12^{\#}$ & $1.42 \pm 0.20^{* *}$ & $136.5 \pm 3.11^{*}$ \\
Serum Urea (mg/dl) & $23.4 \pm 1.3$ & $52.32 \pm 2.0^{\# \#}$ & $25.13 \pm 2.05^{* * *}$ & $1.96 \pm 0.11^{\text {ns }}$ \\
KW/BW ratio & $2.93 \pm 0.07$ & $7.18 \pm 0.08^{\# \# \#}$ & $3.92 \pm 0.09^{* * *}$ & $36.5 \pm 2.43^{*}$ \\
\hline
\end{tabular}

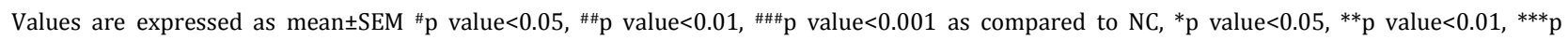
value $<0.001$ as compared to DC

Table 5: Effect of berberine (BBR) on body weight, feed intake, water intake and urine volume

\begin{tabular}{|c|c|c|c|c|c|c|c|c|}
\hline \multirow{2}{*}{$\begin{array}{l}\text { Experimental } \\
\text { groups }\end{array}$} & \multicolumn{2}{|c|}{ Bodyweight (g) } & \multicolumn{2}{|c|}{ Feed intake (g) } & \multicolumn{2}{|c|}{ Water intake (ml) } & \multicolumn{2}{|c|}{ Urine volume (ml) } \\
\hline & Initial & Final & Initial & Final & Initial & Final & Initial & Final \\
\hline $\begin{array}{l}\text { Normal control } \\
\text { (NC) }\end{array}$ & $138 \pm 2.20$ & $146.4 \pm 1.17$ & $14.16 \pm 1.5$ & $20.83 \pm 1.5$ & $43.33 \pm 2.5$ & $13.83 \pm 1.50$ & $5.5 \pm 0.76$ & $9.33 \pm 1.3$ \\
\hline $\begin{array}{l}\text { Diabetic control } \\
\text { (DC) }\end{array}$ & $\begin{array}{l}205.3 \pm 4.63^{\#} \\
\#\end{array}$ & $270 \pm 7.43^{\# \# \# ~}$ & $22.5 \pm 2.3^{\#}$ & $31.16 \pm 1.8^{\# \# \#}$ & $47 \pm 2.4^{\# \#}$ & $76.0 \pm 3.02^{\# \# \#}$ & $25.0 \pm 1.77 \# \#$ & $28.33 \pm 1.9 \# \# \#$ \\
\hline $\begin{array}{l}\text { DC+MET } \\
(100 \mathrm{mg} / \mathrm{kg})\end{array}$ & $234.6 \pm 3.9^{\mathrm{ns}}$ & ${\underset{* *}{* *}}^{193.53 \pm 4.83^{*}}$ & $\begin{array}{l}18.83 \pm \\
1.2^{\text {ns }}\end{array}$ & $16.5 \pm 1.4^{* * *}$ & $42.0 \pm 2.6^{\mathrm{ns}}$ & $26.67 \pm 2.80^{* * *}$ & $13.83 \pm 1.6^{* *}$ & $13.33 \pm 1.6^{* * *}$ \\
\hline $\begin{array}{l}\text { DC+BBR } \\
(75 \mathrm{mg} / \mathrm{kg})\end{array}$ & $211.8 \pm 3.6^{\mathrm{ns}}$ & $215.8 \pm 2.82^{* *}$ & $22.16 \pm 1.7^{\mathrm{ns}}$ & $20.83 \pm 1.19^{* *}$ & $47.5 \pm 2.4^{\mathrm{ns}}$ & $28.33 \pm 2.04^{* *}$ & $18.33 \pm 7.5^{*}$ & $15.33 \pm 1.8^{* *}$ \\
\hline $\begin{array}{l}\mathrm{DC}+\mathrm{BBR} \\
(150 \mathrm{mg} / \mathrm{kg})\end{array}$ & $236.8 \pm 4.3^{\mathrm{ns}}$ & $199.5 \pm 5.6^{* * *}$ & $24.33 \pm 2.18^{\mathrm{ns}}$ & $16.67 \pm 1.5^{* * *}$ & $12.33 \pm 1.14^{\mathrm{ns}}$ & $23.33 \pm 2.10^{* *}$ & $16.16 \pm 1.24^{\mathrm{ns}}$ & $13.5 \pm 2.1^{* *}$ \\
\hline
\end{tabular}

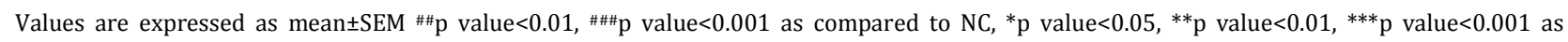
compared to DC

Effect of berberine on histopathology of the pancreas is shown in fig 3. Diabetic rat pancreas shows necrosis of pancreatic islets and surrounding acini. Treatment with berberine for $28 \mathrm{~d}$ exhibited dose-dependent improvement in the pancreas histology. 


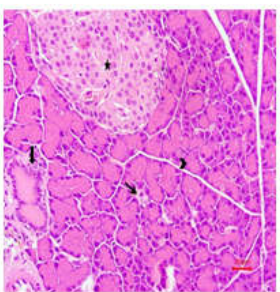

(a)

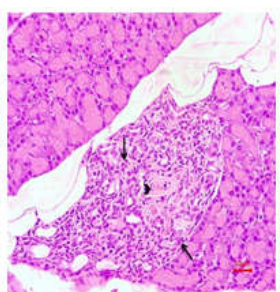

(b)

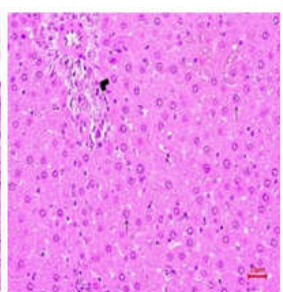

(c)

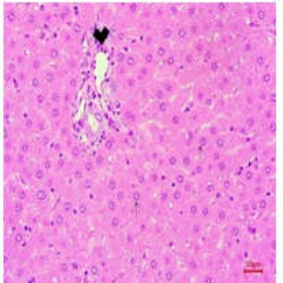

(d)

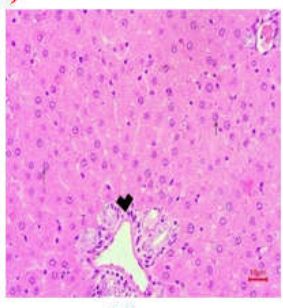

(e)

Fig. 3: (a-e) Effect of berberine on histology of pancreas in different experimental groups, (a) Normal histological structure of rat pancreas showing normal histology, (b) Diabetic rat pancreas shows necrosis of Islets of Langerhans (arrow) and surrounding acini of exocrine pancreas (arrowhead), (c) Diabetic rats treated with metformin $(100 \mathrm{mg} / \mathrm{kg}) \mathrm{show}$ is normal histology, acinus (arrowhead), interlobular duct (large arrow), intercalated duct (small arrow), Islet of Langerhans (star), (d) Oral administration of 75 mg/kg of BBR in diabetic rats show slight changes in pancreas, (e) treatment with $150 \mathrm{mg} / \mathrm{kg}$ of BBR significantly improved in the histological structure of pancreas. Photomicrographs are taken under 400X magnification

Fig. 4 shows effect of berberine on histopathology of kidney. Diabetic rat kidney shows cytoplasmic vacuolation of tubules, tubular dilation and lymphocytic infiltration. Treatment with berberine for $28 \mathrm{~d}$ exhibited dose-dependent improvement in the kidney histology.

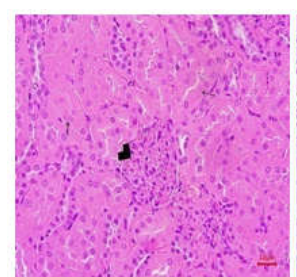

(a)

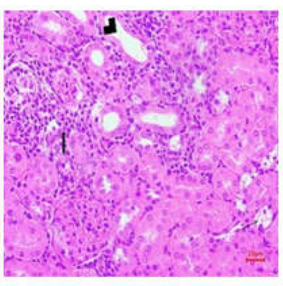

(b)

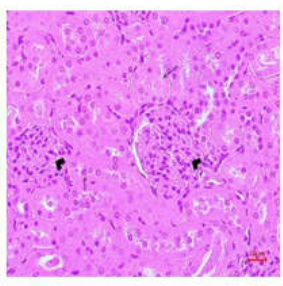

(c)

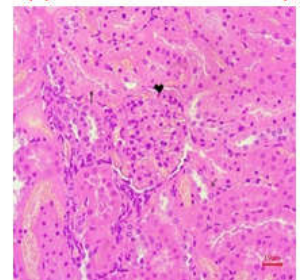

(d)

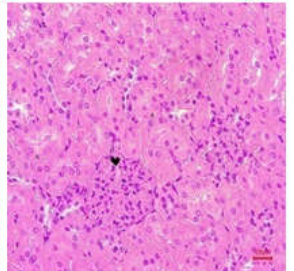

(e)

Fig. 4: (a-e) Effect of berberine on histology of pancreas in different experimental groups. (a) Normal histological structure of kidney showing the normal histological structure, (b) Diabetic rat kidney showing cytoplasmic vacuolation of tubules, tubular dilation and lymphocytic infiltration, (c) Diabetic rats treated with metformin (100 mg/kg) (d) Oral administration of $75 \mathrm{mg} / \mathrm{kg}$ of berberine for $28 \mathrm{~d}$ in diabetic rats show slight changes in glomerulus and tubules; (e) Treatment with $150 \mathrm{mg} / \mathrm{kg}$ berberine shows improvement in histological structure of glomerulus. Photomicrographs are taken under 400X magnification

\section{DISCUSSION}

Diabetes mellitus is a common endocrine disorder characterized by chronic hyperglycemia due to either insufficient insulin production by pancreatic beta cells or by cellular resistance to insulin [25]. According to IDF, one-third of our elderly population suffers from diabetes mellitus [26]. Importantly, patients with type II diabetes mellitus display higher risk to develop severe complications such as cardiomyopathy, nephropathy, neuropathy and retinopathy [27-30].

In the present study, the effect of berberine (BBR) on diabetic complications like nephropathy and cardiomyopathy were assessed using a high-fat diet (HFD) and low dose streptozotocin (STZ) induced diabetic rat model. STZ has been known to mediate pancreatic $\beta$-cell toxicity by generating reactive oxygen species [31]. HFD on the other hand is known to increase visceral fat depots by altering the carbohydrate and lipid metabolism, thereby leading to insulin resistance [32]. This model of HFD-low dose STZ induced diabetes thus mimics the condition of insulin resistance observed currently in the society because of a sedentary lifestyle and modernized dietary habits.

In this present study, the administration of STZ-HFD for $4 \mathrm{w}$ induced type II diabetes mellitus in the experimental animals as indicated by 
rise in fasting blood glucose and is in accordance with earlier studies reported [33]. Postprandial blood glucose level plays an important role in diabetes-associated complications. Hence we carried out fasting blood glucose level and oral glucose tolerance test.

In the present study significant increase in fasting and postprandial blood glucose level observed in HFD-STZ induced diabetic animals indicates various possibilities including injury to pancreatic beta cells or reduced peripheral utilization of blood glucose by the target tissues or increased production of glucose by liver cells or increased breakdown of glycogen in the liver [34-36]. Decrease in the blood glucose levels as observed in BBR treated groups indicates the role of BBR in improving glycemic control either through pancreatic cells regeneration or by improving the peripheral utilization of glucose as in accordance with earlier studies [37]. Measurement of serum insulin is an important aspect for antidiabetic research as it provides an idea of whether the drug improves the condition of damaged beta cells of pancreas or not [38]. In the present study, improvement in serum insulin in BBR treated groups as compared to diabetic control rats indicates that BBR either regenerate pancreatic beta cells or may improve insulin secretion from residual $\beta$-cell of the pancreas. The claim is further strengthened from the histopathological study of pancreas, which showed improved histology of pancreas in drugtreated experimental groups.

Persistent rise in blood glucose level results in long term diabetic complications mainly because of the formation of glycosylated haemoglobin (HbA1c), which further damages the blood vessels through oxidative stress [39-40]. In the present study, oral administration of BBR significantly decreased in HbA1c levels, possibly by preventing oxidative damage caused by glycation reaction in diabetic conditions as a result of decreased blood glucose level and increased insulin secretion.

The antihyperglycemic effect of BBR could be connected to its ability to increase insulin secretion and glucose storage as glycogen in the liver and skeletal muscles of HFD and STZ induced type II diabetic rats. In addition, glycogen may be considered a reliable marker for assessing the antihyperglycemic potential of any drug. Generally, decreased glycogen synthesis, increased glycogenolysis and increased hepatic glucose production are the major symptoms in type II diabetes.

In the study, the increased liver glycogen and skeletal glycogen content after treatment with berberine could be attributed to an amelioration of the glycogenolytic and gluconeogenic pathway secondary to the increase of insulin level in the blood.

Earlier studies have shown that in STZ-HFD diabetic rats, hyperglycemia is associated with hypercholesterolemia and hypertriglyceridemia, which play a key role in the pathogenesis of diabetic cardiomyopathy. Moreover, the rate of free fatty acid uptake by myocardium is inversely proportional to the severity of the myocardial dysfunction [15]. Dyslipidaemia has been the major predictor of cardiaovascular adverse events in diabetic patients [41]. Elevated total cholesterol (T-CH), triglycerides (TG), low-density lipoproteins (LDL-CH), very low-density lipoproteins (VLDL-CH) levels in diabetic rats was reduced and decrease in HDL levels in diabetic rats was improved by BBR treatment indicating its beneficial effect on cardiovascular risk of diabetic animals. In particular, LDL-CH being involved in the transport of cholesterol from the liver to peripheral tissues is the key factor in atherogenesis [42]. The oxidative modification of LDL-CH is implicated in the atherosclerotic plaque in the blood vessels.

The atherogenic index ( $\mathrm{AI})$, which indicates the deposition of fatty plaque in blood vessels is correlated to cardiovascular disease [43] In the present study, a decrease in AI and CRI in BBR treated rats as compared to diabetic control rats indicated that BBR may decrease deposition of fatty plaque in blood vessels. Thus the significant reduction of $\mathrm{AI}$ and $\mathrm{CRI}$ demonstrates the potential of berberine treatment on reducing the risk of cardiovascular complications.

Increased production of reactive oxygen species (ROS) and reduced cellular antioxidant mechanisms contribute to myocardial damage, apoptosis and then the remodelling. Moreover, it also leads to disturbances of myocardial energetics leading to loss of efficiency of myocardium. Since oxidative stress is a major factor contributing in the development of diabetic cardiomyopathy, the anti-oxidant mechanism of BBR may be one of the factors responsible for its protective effect against cardiomyopathy in diabetes mellitus. Type II diabetes mellitus induced by HFD-STZ resulted in classical metabolic disorder that exhibits not only hyperglycemia but also severe oxidative stress in the animals. This effect was evident from the reduced superoxide dismutase and catalase levels and increased MDA levels in the diabetic rats. It is apparent that BBR treatment increased the levels of catalase and superoxide dismutase while reduced the levels of MDA in diabetic rats indicating reduced lipid peroxidation. Antioxidant activity of BBR in type II diabetes mellitus presents a potential benefit over the conventional treatments that do not interfere with the disease progression process.

Experimentally induced diabetes has been shown to cause an increase in the accumulation of protein and collagen formation. This causes structural and functional changes in the cardiac tissue, which causes myocardial fibrosis and stiffness resulting in cardiac dysfunction. Fibrous tissue formation and accumulation of collagen increases the left ventricular mass in diabetic rats [44]. Treatment with BBR could attenuate both cardiac and left ventricular hypertrophy indices significantly, thereby indicating its preventive effect on cardiac remodeling.

In STZ-HFD diabetes, persistent hyperglycemia and other pathological factors like reactive oxygen species (ROS), glycation of proteins, lipids and vital molecules of the cell, inflammatory cytokines etc. cause substantial damage to the kidney. Such changes in diabetic kidney result in loss of nephrons and therefore increased formation of urine. In addition to this, glomerular basement membrane thickening, glomerulosclerosis and increase in mesangial matrix deposition also results in loss of renal function. Not only glucose toxicity but also the low-grade renal tissue inflammation leads to renal tubular damage as well as alteration of glomerular filtration barrier, loss of glomerular charge selectivity and loss of glomerular size selectivity [45]. Diabetic nephropathy progresses from microalbuminuria to macroalbuminuria leading to end-stage renal disease (ESRD). Microalbuminuria is also a strong predictor of cardiovascular disease in patients with diabetes [46].

In the present study, we evaluated kidney function parameters, including blood urea nitrogen (BUN), serum creatinine, plasma urea and uric acid, to assess the effect of BBR on diabetic nephropathy. Treatment with BBR reduced the level of these parameters indicating a protective effect of BBR against inflammation of renal tissue and kidney damage. Proteinuria is considered to be the gold standard for screening and staging of diabetic renal damage. Diabetic control animals in our study developed prominent proteinuria. However, treatment with BBR reduced urinary protein indicating a protective effect of BBR against renal glomerular and tubular damage. This nephroprotective effect is further confirmed from the histopathological study of the kidney, which shows normal histology, reduction in cytoplasmic vacuolation of tubules, tubular dilation and lymphocytic infiltration. Moreover, in the present study, a decrease in the urine volume by BBR as compared to diabetic control indicates the possible role of BBR in the restoration of abnormalities in urine volume.

Weight gain is an important characteristic of type II diabetes mellitus, which is due to the consumption of a diet rich in energy in the form of saturated fats (lard) and its deposition in various body fat pads. During the experimental period of $28 \mathrm{~d}$, we noticed that the rat fed on a high-fat diet showed hyperphagia with an initial increase in body weight. Significant reduction in the body weight and basal metabolic index (BMI) during the treatment period with berberine as compared to disease control indicates homeostasis in carbohydrate and protein metabolism.

Significant increase in feed intake and water intake in diabetic animals could be due to poor glycemic control. Reduction in feed intake and water intake after treatment with BBR might be a result of insulin-like action or improvement in peripheral glucose utilization. 


\section{CONCLUSION}

Conclusively, our study demonstrates that a combination of high-fat diet and streptozotocin injection effectively generated a rat model that mimics the natural history and metabolic characteristics of type II diabetes in humans. Observations from our study demonstrate that berberine effectively showed antidiabetic activity at dosedependent manner $(75 \mathrm{mg} / \mathrm{kg}$ and $150 \mathrm{mg} / \mathrm{kg}$ ) in diabetic animals. BBR also showed a beneficial effect on parameters of diabetic nephropathy and cardiomyopathy, indicating less cardiac and renal damage inflicted by diabetes mellitus.

\section{ACKNOWLEDGEMENT}

Authors are thankful to the Principal and Management of Progressive Education Society for providing the research facilities to carry out the research work.

\section{FUNDING}

$\mathrm{Nil}$

\section{AUTHORS CONTRIBUTIONS}

Deepti Bandawane, Shruti Mooliya and Shailaja Jadhav designed the study, carried it out, analysed the data, wrote and revised the manuscript.

\section{CONFLICT OF INTERESTS}

All authors declare that there is no conflict of interest.

\section{REFERENCES}

1. Shetty P. India's diabetes time bomb. Nature 2012;485:S14-6.

2. Srinivasan K, Viswanad B, Asrat L, Kaul CL, Ramarao P. Combination of high-fat diet-fed and low-dose streptozotocintreated rat: a model for type 2 diabetes and pharmacological screening. Pharmacol Res 2005;52:313-20.

3. Zheng T, Shu G, Yang Z, Mo S, Zhao Y, Mei Z. Antidiabetic effect of total saponins from Entadaphaseoloides (L.) Merr. in type 2 diabetic rats. J Ethnopharmacol 2012;139:814-21.

4. Hamza N, Berke B, Cheze C, Agli AN, Robinson P, Gin H, et al. Prevention of type 2 diabetes induced by high fat diet in the C$57 \mathrm{BL} / 6 \mathrm{~J}$ mouse by two medicinal plants used in traditional treatment of diabetes in the East of Algeria. J Ethnopharmacol 2010;128:513-8.

5. Stumvoll M, Goldstein BJ, Van Haeften TW. Type 2 diabetes principles of pathogenesis and therapy. Lancet 2005;365:1333-46.

6. Abdel Rahman MM, Mahmoud AM, Bastawy NA, Eissa HM Antihyperlipidemic and myocardial enhancing effects of berberine in high-fat diet/streptozotocin-induced diabetic rats: possible role of adiponectin. Int J Nutr Food Sci 2017;2:1-7.

7. Wang Y, Campbell T, Perry B, Beaurepaire C, Qin L Hypoglycaemic and insulin-sensitizing effects of Berberine in high fat diet and streptozotocin-induced diabetic rats. Metabol Clin Exp 2011;60:298-305

8. Li Z, Geng Y, Jiang J, Kong W. Antioxidant and antiinflammatory activities of berberine in the treatment of diabetes mellitus. Evidence-Based Complementary and Alternative Medicine 2014:1-12. https://doi.org/10.1155/ $2014 / 289264$

9. Liu Y, Zhao Y, Guo D, Liu W, Liu Y. Synergistic antimicrobial activity of berberine hydrochloride, baicalein and borneo against Candida albicans. Chinese Herbal Med 2017;9:353-7.

10. Almani SA, Qureshi F, Shaikh TZ, Uqaili AA, Khoharo HK. Free radical scavenging activity of Berberine in acetaminopheninduced liver injury. Int I Surgery Med 2017;3:27-36.

11. Ni YX. Therapeutic effect of berberine on 60 patients with type 2 diabetes mellitus and experimental research. Chinese Modern Dev 1988;8:711-3.

12. Srinivasan K, Viswanad B, Asrat L, Kaul CL, Ramarao P. Combination of high-fat diet-fed and low-dose streptozotocintreated rat: a model for type 2 diabetes and pharmacological screening. Pharmacol Res 2005:52;313-20.

13. Noveli EL, Dini YS, Galhardi CM, Ebaid GM, Roadrignes HG, Mani F. Anthropometrical parameters and markers of obesity in rats. Lab Animals 2007;41:111-9.
14. Lakshmi A, Rao YM, Bhargavi CH, Seelam U. Antidiabetic and wound healing activity of various bark extracts of Polyalthia longifolia. Asian J Pharm Clin Res 2011:4;109-13.

15. Carrol NV, Longley RW, Roe JH. The determination of glycogen in liver and muscle by use of anthrone reagent. J Biol Chem 1956;220:583-93.

16. Purohit A, Ram H. Hypolipidemic and antiatherosclerotic effects of Prosopis cineraria bark extract in experimentally induced hyperlipidemic rabbits. Asian J Pharm Clin Res 2012:5;106-9.

17. Friedewald WT, Levy RI, Fredrickson DS. Estimation of the concentration of low-density lipoprotein cholesterol in plasma without use of the preparative ultracentrifuge. Clin Chem 1972;18:499-502.

18. Dobiasova M, Frohlish J. The plasma parameter log (TG/HDL-C) as atherogenic index correlation with lipoprotein depleted plasma. Clin Biochem 2001;34:350-7.

19. Alladi S, Shanmugasundaram KR. Induction of hypercholesterolemia by supplementing soy protein with acetate generating amino acid. Nutr Res Int 1989;40:893-9.

20. Parmar K, Prajapati A, Patel S, Patel M, Patel B. Cardioprotective effect of lisinopril in streptozotocin-induced type-II diabetic rats. Acta Endocrinol 2012;8:177-88.

21. Marklund SL. Pyrogallol autooxidation. In: Greenwald RA. Ed. Handbook of methods for oxygen radical research. Boca Raton: CRC Press; 1985. p. 243-4.

22. Sahreen S, Khan MR, Khan RA. Hepatoprotective effects of methanol extract of Carissa opaca leaves on $\mathrm{CCl}_{4}$ induced damage in rats. Compl Alternat Med 2011;11:1-10.

23. Kumar S, Kumar V, Prakash O. Antidiabetic, hypolipidemic and histopathological analysis of Dillenia indica (L.) leaves on alloxan-induced diabetic rats. Asian Pac J Trop Med 2010;4:347-52.

24. Jaydeokar AV, Bandawane DD, Bibave KH, Patil TV. Hepatoprotective potential of Cassia auriculata root on ethanol and antitubercular drug-induced hepatotoxicity in the experimental model. Pharm Biol 2014;52:344-55.

25. Gale EAM, Anderson JU. Diabetes mellitus and other disorders of metabolism. In: Kumar P, Clark M. Editors. Clin Med $5^{\text {th }}$ edition London: WB Saunders 2002;1069:101-20.

26. International Diabetes Federation; 2017.

27. Boudina S, Abel ED. Diabetic cardiomyopathy revisited. Circulation 2007;115:3213-23

28. Daousi C, MacFarlane IA, Woodward A, Nurmikko TJ, Bundred PE, Benbow SJ. Chronic painful peripheral neuropathy in an urban community: a controlled comparison of people with and without diabetes. Diabetic Med 2004;21:976-82.

29. Retnakaran R, Cull CA, Thorne KI, Adler AI, Holman RR. Risk factors for renal dysfunction in type 2 diabetes: UK prospective diabetes study 74. Diabetes 2006;55:1832-9.

30. Semeraro F, Cancarini A, Rezzola S, Romano MR, Costagliola C Diabetic retinopathy: vascular and inflammatory disease: Therapeutic implications. J Diabetes Res 2015;45:517-27.

31. Fukudome D, Matsuda M, Kawasaki T, Ago Y, Matsuda T. A radical scavenger counteracts diabetes in multiple low dose streptozotocin treated mice. Eur J Pharmacol 2008;583:164-9.

32. Brown JL, Spicer MT, Spicer LJ. Effect of a high-fat diet on body composition and hormone responses to glucose tolerance tests. Endocrine 2002;19:327-32.

33. Mahmoud AM, Ahmed OM, Ashour MB, Abdel Moneim A. In vivo and invitro antidiabetic effect of citrus flavonoids; a study on the mechanism of action. Int J Diabetes Dev Ctries 2015;35:250-63

34. Beck Nielsen H, Hother Nielsen O, Staehr P. Is hepatic glucose production increased in type 2 diabetes mellitus? Curr Diabetes Reports 2002;2:231-6.

35. Raju J, Gupta D, Rao AR, Yadava PK, Baquer NZ. Trigonella foenum graecum (fenugreek) seed powder improves glucose homeostasis in alloxan diabetic rat's tissues by reserving the altered glycolytic, gluconeogenic and lipogenic enzymes. Mol Cell Biochem 2001;224:45-51.

36. Gold AH. The effect of diabetes and insulin on liver glycogen synthetase activation. J Biol Chem 1970;245:903-5.

37. Chang W, Zhang M, Li J, Meng Z, Wei S. Berberine improves insulin resistance in cardiomyocytes via activation of 5'- 
adenosine monophosphate-activated protein kinase. Metabo 2013;62:1159-67.

38. Wang ZQ, Lu FE, Yan ZQ. Facilitating effects of berberine on rats pancreatic islets through modulating hepatic nuclear factor- $4 \mathrm{o}$ expression and glucokinase activity. World J Gastroenterol 2008;4:6004-11.

39. Shirwaikar A, Rajendran K, Barik R. Effect of Garuga pinnata roxb aqueous bark extract on tissue antioxidant activity in streptozotocin-nicotinamide induced type II diabetic rats. Pharm Biol 2007;45:205-9.

40. Tanjung E, Iskandar $\mathrm{K}$, Suhartono E. Antidiabetic and antioxidant activity of Jackfruit (Artocarpus heterophyllus) extract. J Med Bioengg 2015;4:318-23.

41. Nakayama H, Morozumi T, Nanto S. Abnormal myocardial free fatty acid utilization deteriorates with morphological changes in the hypertensive heart. Japanese Circ 2001;65:783-7.
42. Bandawane DD, Jadhav SB, Juvekar AR. Exploration of protective effect of hydroalcoholic extract of Alstonia scholaris bark in STZ-induced early diabetic nephropathy model in rats. Indian Drugs 2019;56:69-78.

43. Marwa AM, Ayman MM, Nermin AB, Hassan ME. Berberine in high-fat diet/streptozotocin-induced diabetic rats; possible role of adiponectin. Nutr Food Sci Int J 2017;2:1-7.

44. Veber VR, Lobzin JV, Rubanova MP, Gubskaya PM, Zhmailova SV, Karev VE, et al. Peculiarities of myocardium remodeling under adrenergic and cholinergic types of acute stress in an experiment. Med Acad J 2014;14:22-7.

45. Nakamura Y, Myers B. Charge selectivity of proteinuria in diabetic glomerulopathy. Diabetes 1988;37:1202-11.

46. Ruggenenti P, Remuzzi G. Time to abandon microalbuminuria? Kidney Int 2006;70:1214-22. 